\title{
Progress in the Diagnosis and Treatment of Idiopathic Pulmonary Fibrosis
}

\author{
Randall S Schwartz, MD¹ and Marilyn Glassberg, MD, FACP, FCCP2-5 \\ 1. Pulmonary and Critical Care Fellow, Jackson Memorial Hospital, University of Miami, Miami, Florida, US; 2. Director, Interstitial Lung Disease Program, \\ Jackson Memorial Hospital, University of Miami, Miami, Florida, US; 3. Director, Pulmonary Diseases at Interdisciplinary Stem Cell Institute, \\ Jackson Memorial Hospital, University of Miami, Miami, Florida, US; 4. Professor of Medicine, Surgery, and Pediatrics, Jackson Memorial Hospital, \\ University of Miami, Miami, Florida, US; 5. Vice-Chairman of Medicine for Diversity and Innovation,
}

Jackson Memorial Hospital, University of Miami, Miami, Florida, uS

DOl: http://doi.org/10.17925/USRPD.2016.01.01.22

\begin{abstract}
Current management of patients with idiopathic pulmonary fibrosis (IPF) requires attention to the exclusion of other causes of interstitial lung disease and either a definitive pattern on high-resolution computed tomography (HRCT) or a suggestive HRCT plus surgical lung biopsy. The main differential considerations include chronic hypersensitivity pneumonitis and connective tissue disease-associated interstitial lung disease (CTILD). Treatment includes smoking cessation, anti-reflux therapy, and the therapeutic option of one of two recently approved drugs, pirfenidone or nintedanib. IPF remains a deadly disease despite these drugs; thus the greatest emphasis should be on exclusion of alternative, potentially favorable diagnoses, continued option for enrollment in ongoing clinical trials, and, for eligible patients, early lung transplant evaluation.
\end{abstract}

\section{Keywords}

Fibrosis, idiopathic, interstitial, IPF, nintedanib, pirfenidone

Disclosure: Randall S Schwartz, MD, has nothing to disclose in relation to this article. Marilyn Glassberg, MD, FACP, FCCP, serves as a consultant/advisory board member for Boehringer Ingelheim, Genentech, and Mesoblast. This article is a short opinion piece and has not been submitted to external peer reviewers. No funding was received in the publication of this article.

Open Access: This article is published under the Creative Commons Attribution Noncommercial License, which permits any noncommercial use, distribution, adaptation, and reproduction provided the original author(s) and source are given appropriate credit.

Received: October 16, 2015 Published Online: December 1, 2015 Citation: US Respiratory \& Pulmonary Diseases, 2016;1(1):22-4

Correspondence: Marilyn Glassberg, MD, FACP, FCCP, Jackson Memorial Hospital, University of Miami, Miami, Florida, US. E: MGlassbe@med.miami.edu

\section{Diagnosis}

Idiopathic pulmonary fibrosis (IPF) is the most common of the idiopathic interstitial pneumonias ${ }^{1}$ and accounts for about $20 \%$ of all interstitial lung diseases (ILD). ${ }^{2}$ IPF should be considered in all adult patients with unexplained chronic exertional dyspnea, ${ }^{3}$ though it is rare in patients less than 50 years of age. ${ }^{4,5}$ The latest guidelines for diagnosis require exclusion of other known causes of ILD and presence of either a characteristic pattern on high-resolution computed tomography (HRCT) or specific combinations of HRCT and surgical lung biopsy with the pattern of usual interstitial pneumonia (UIP). ${ }^{3}$ Other disease processes that may cause UIP include collagen vascular disease (CT-ILD), drug toxicity, chronic hypersensitivity pneumonitis (CHP), asbestosis, and Hermansky-Pudlak syndrome. ${ }^{6}$ Diagnosis of an underlying cause, if known, is of great significance in terms of treatment and survival. For instance, in one study, patients with UIP secondary to CT-ILD lived 63 \% longer than those with idiopathic UIP. ${ }^{7}$

Classic HRCT patterns seen in IPF include a basilar and subpleural predominant distribution of reticulation and honeycombing, commonly with, though not requiring, traction bronchiectasis. ${ }^{8}$ Presence of ground glass does not exclude UIP so long as there is a greater degree of reticulation. ${ }^{8}$ Emphysematous changes may complicate HRCT interpretation and has been shown to result in mistaking UIP for chronic pulmonary emphysema with fibrosis (CPEF) as well as nonspecific interstitial pneumonia (NSIP). ${ }^{9}$ Appearance of the UIP distribution may be asymmetrical in up to $25 \%$ of cases. ${ }^{10}$

The most common differential diagnoses for IPF are CHP, CT-ILD, and pneumoconiosis with particular emphasis on asbestosis. ${ }^{3}$ Concomitant features such as centrilobular nodules, air trapping, and relative sparing of the bases may be suggestive of hypersensitivity pneumonitis; pleural plaques suggest asbestosis; and septal or bronchovascular nodules may be present in sarcoidosis. ${ }^{11}$ CT-ILD should be considered in the presence of pleural effusion and/or pleural thickening, as well as esophageal dilation. ${ }^{11}$

Differentiating CHP from UIP/IPF may be difficult, as many times the offending antigen may not be discoverable. ${ }^{12}$ While bronchoalveolar lavage (BAL) showing $>40 \%$ lymphocytes suggests a diagnosis of $\mathrm{CHP}$ and gene expression signatures have been shown to distinguish UIP from $\mathrm{CHP}_{1}^{13}$ retrospective data suggest only $8 \%$ of patients with a UIP pattern on HRCT have BALs suggestive of alternative diagnoses, ${ }^{14}$ and hence current guidelines recommend against routine BAL when evaluating for IPF. ${ }^{3}$ 
IPF may present with a low-titer positive antinuclear antibody (ANA) and/or rheumatoid factor (RF) at a rate similar to that of healthy controls. ${ }^{15}$ In such patients, further evaluation for connective tissue disease (CTD) should be pursued, including both clinical and serologic workup. In the absence of additional evidence for CTD, a diagnosis of IPF may be appropriate, though periodic repeat evaluations for CTD should be done. ${ }^{3}$ Distinguishing idiopathic pneumonia with autoimmune features (IPAF) from CT-ILD is critical, but difficult, due in part to the lack of reliable biomarkers. ${ }^{16}$

\section{Failed Therapies}

Potentially harmful medications in the treatment of IPF include warfarin ${ }^{17}$ and the combination of prednisone, azathioprine, and N-acetylcysteine. ${ }^{18}$ Sildenafil has failed to show improvement in forced vital capacity (FVC), dyspnea score, and mortality. ${ }^{19,20}$ A signal of harm was displayed with the use of selective endothelin receptor antagonist (ERA), ambrisentan, even in the presence of pulmonary hypertension $(\mathrm{PH}) .{ }^{21}$ In general, nonselective ERAs (bosentan, macitentan) should not be used in IPF, though it remains unclear if there may be a beneficial role in patients with PH secondary to IPF.22-24

\section{Current Principles of Management}

Gastroesophageal reflux (GER) is seen in up to $90 \%$ of patients with IPF, but often clinically silent. ${ }^{25-27}$ Antiacid treatments may decrease the risk of microaspiration-associated lung injury and have been shown to decrease the rate of FVC decline. ${ }^{28,29}$ Most studies have included proton pump inhibitors (PPIS) more than histamine-2 receptor antagonists (H2RAs), without a recommendation for one class over the other. More recently, PPIs have been suggested to have more pleiotropic effects, including suppression of profibrotic proteins. ${ }^{30,31}$

\section{Pirfenidone}

Pirfenidone is an antifibrotic agent first approved for use in IPF in Japan in 2008 following a trial that showed a 43 \% reduction in the rate of decline in FVC and improved progression-free survival. ${ }^{32}$ This was followed by two CAPACITY (Clinical Studies Assessing Pirfenidone in Idiopathic Pulmonary Fibrosis: Research of Efficacy and Safety Outcomes) trials. ${ }^{33}$ The first trial, 004 , showed a decline in FVC of $8.0 \%$ after 72 weeks with $2,403 \mathrm{mg}$ /day versus a $12.4 \%$ loss in the placebo group. The 006 trial, however, did not maintain this effect through 72 weeks. Pooled data from both trials suggested benefit, though the Food and Drug Administration (FDA) requested another study be done to clarify the discrepancy. The ASCEND (Assessment of Pirfenidone to Confirm Efficacy and Safety in Idiopathic Pulmonary Fibrosis) inclusion criteria were stricter, requiring lung biopsy if HRCT findings were not classic for IPF. ${ }^{34}$ The 52-week protocol showed half the number of patients in the pirfenidone arm experienced a decline in $\mathrm{FVC} \geq 10 \%$ compared with those in the placebo group. More impressively, 63 patients receiving pirfenidone experienced no loss of vital capacity, while this occurred in only 27 patients given placebo. Fewer patients in the treatment arm experienced a decline of $\geq 50 \mathrm{~m}$ in their 6-minute walk test. These results led to the FDA approval of pirfenidone for the treatment of IPF in the US in 2014. This year, a sensitivity analysis of ASCEND demonstrated that at week 52, the proportion of patients with a $10 \%$ decline in FVC or death was decreased by $47.8 \%$, and the proportion of patients with no decline was increased by $132.5 \%{ }^{35}$ The most common adverse effects of pirfenidone included cough, nausea, headache, diarrhea, upper respiratory infection, fatigue, and rash, leading to discontinuation of the drug in $14.4 \%$ of patients in ASCEND compared to a $10.8 \%$ placebo discontinuation rate. Elevation of liver enzymes $>3$ times upper limit of normal occurred in $<3 \%$ of patients. ${ }^{34}$ Later, 178 patients who had previously been randomized to the control group in CAPACITY were included in an open-label extension, RECAP. In this study, the mean decline in FVC at week 60 was $-5.9 \%$, an even better outcome than in the CAPACITY treatment group (-7.0\%). ${ }^{36}$ New data recently presented at the CHEST 2015 meeting from a pooling of the CAPACITY and ASCEND trials indicate that pirfenidone reduced both IPF-related and treatment emergent IPF-related mortality (HR 0.55 and 0.47 , respectively). ${ }^{37}$

\section{Nintedanib}

Nintedanib is a tyrosine kinase inhibitor with multiple potential therapeutic pathways in the treatment of IPF, including inhibition of vascular endothelial growth factor (VEGFR), platelet-derived growth factor receptor (PDGFR), and basic fibroblast growth factor receptor (bFGFR), each having roles in either endothelial or smooth muscle cell proliferation, and/or fibrogenesis. ${ }^{38-40}$ In To Improve Pulmonary Fibrosis with BIBF 1120 (TOMORROW), nintedanib reduced annual FVC decline by $68.4 \%$ (130 ml/year) ( $p=0.06$ closed testing for multiplicity correction; $p=0.01$ hierarchical testing), led to less acute exacerbations (2.4 versus 15.7 per 100 patient-years; $p=0.02$ ), and led to a 4.8-point improvement in the St George's Respiratory Questionnaire (SGRQ) ( $p=0.007) .{ }^{41}$ Later came INPULSIS-1 and INPULSIS-2 (Safety and Efficacy of BIBF 1120 at High Dose in IPF Patients I and II, respectively). ${ }^{42}$ Both were 52 -week protocols where neither found a mortality benefit nor reduction in acute IPF exacerbation rate. However, patients on nintedanib had an average $52 \%$ reduction in FVC loss, representing about $125 \mathrm{ml}$ spared annually. ${ }^{42}$ The most common adverse event was diarrhea (>60\%), followed by nausea. Elevation of liver function tests occurred in about $5 \%$ of patients on nintedanib. During the INPULSIS series, 10 patients on nintedanib suffered myocardial infarctions, compared with two patients receiving placebo. Worth noting is that some patients enrolled in INPULSIS were included with HRCT interpreted as "probable UIP" and not confirmed with biopsy. It is unclear whether this may suggest the benefit of nintedanib in non-UIP ILD or rather an underestimation of its effect in true UIP due to inappropriate inclusion criteria.

Comparison of the available data shows similar reductions in FVC decline of $45.1 \%$ with pirfenidone, and $52.2 \%$ with nintedanib. With time, nintedanib may show an improvement in mortality comparable to that of pirfenidone. The practical interpretation and application of the differences in data between the two drugs is unclear in that the groups of patients studied were not the same. The selection of one medication over the other should be done on a case by case basis, following a discussion with the patient regarding dose scheduling (nintedanib is twice daily, pirfenidone three times daily), adverse effects, and cost/ accessibility. Although there are plans to study the two drugs together, no data are currently available to support combination therapy or to prefer one drug over the other.

Current guidelines do not address appropriate timing for referral for patients with IPF for lung transplantation. ${ }^{43}$ Consider referring patients with IPF for lung transplant evaluation if they have dyspnea with routine 
daily activities and are requiring oxygen therapy with an anticipated survival of $<5$ years. Regarding single- versus double-lung transplant, a recent meta-analysis of available observational studies from 1990 to 2013 did not show any difference in mortality after adjustment for patient characteristics. ${ }^{44}$ Ongoing cell-based therapy trials may promote new directions in the management of this fatal disease. ${ }^{45}$

\section{Conclusion}

Despite the recent addition of two medications for IPF that slow lung function decline, IPF remains a deadly disease. Avoidance of smoking should be strongly advised, and poignant management of comorbidities such as GER should be undertaken. We have entered a new era in the management of IPF, but curing the disease remains a current goal.
1. King TE Jr, Schwarz MI, Brown K, et al., Idiopathic pulmonary fibrosis: relationship between histopathologic features and mortality, Am J Respir Crit Care Med, 2001;164:1025-32.

2. Karakatsani A, Papakosta D, Rapti A, et al., Epidemiology of interstitial lung diseases in Greece, Respir Med, 2009;103:1122-9.

3. Raghu G, Collard HR, Egan JJ, et al., ATS/ERS/JRS/ALAT Committee on Idiopathic Pulmonary Fibrosis, An official ATS ERS/JRS/ALAT statement: idiopathic pulmonary fibrosis: evidence-based guidelines for diagnosis and management, Am J Respir Crit Care Med, 2011;183:788.

4. Raghu G, Weycker D, Edelsberg J, et al., Incidence and prevalence of idiopathic pulmonary fibrosis, Am J Respir Crit Care Med, 2006;174:810-6.

5. Nadrous HF, Myers JL, Decker PA, Ryu JH, Idiopathic pulmonary fibrosis in patients younger than 50 years, Mayo Clin Proc, 2005;80:37-40.

6. American Thoracic Society, European Respiratory Society, American Thoracic Society/European Respiratory Society International Multidisciplinary Consensus Classification of the Idiopathic Interstitial Pneumonias, This joint statement of the American Thoracic Society (ATS), and the European Respiratory Society (ERS) was adopted by the ATS board of directors, June 2001 and by the ERS Executive Committee, June 2001, Am J Respir Crit Care Med, 2002:165:277-304.

7. Park JH, Kim DS, Park IN, et al., Prognosis of fibrotic interstitial pneumonia, Am J Resp Crit Care Med, 2007;175:705-11.

8. Lynch DA, Godwin JD, Safrin S, et al., Idiopathic Pulmonary Fibrosis Study Group, High-resolution computed tomography in idiopathic pulmonary fibrosis: diagnosis and prognosis, Am J Respir Crit Care Med, 2005;172:488-93.

9. Akira $\mathrm{M}$, Inoue $\mathrm{Y}$, Kitaichi $\mathrm{M}$, et al., Usual interstitial pneumonia and nonspecific interstitial pneumonia with and without concurrent emphysema: thin-section CT findings, Radiology, 2009:251:271-9.

10. Tcherakian C, Cottin V, Brillet PY, et al., Progression of idiopathic pulmonary fibrosis: lessons from asymmetrical disease, Thorax, 2011;66:226-31.

11. Sverzellati N, Highlights of HRCT imaging in IPF, Respir Res, 2013;14(Suppl. 1): S3

12. Vourlekis JS, Schwarz MI, Cherniack RM, et al., The effect of pulmonary fibrosis on survival in patients with hypersensitivity pulmonary fibrosis on survival in patients

13. Selman M, Pardo A, Barrera L, et al., Gene expression profiles distinguish idiopathic pulmonary fibrosis from hypersensitivity pneumonitis, Am J Respir Crit Care Med, 2006;173:188-98.

14. Ohshimo S, Bonella F, Cui A, et al., Significance of bronchoalveolar lavage for the diagnosis of idiopathic pulmonary fibrosis, Am J Respir Crit Care Med, 2009;179:1043-7.

15. Lee JS, Kim EJ, Lynch KL, et al., Prevalence and clinical significance of circulating autoantibodies in idiopathic pulmonary fibrosis, Respir Med, 2013;107:249-55.
16. Fischer A Antoniou KM, Brown KK, et al., ERS/ATS Task Force on Undifferentiated Forms of CTD-ILD, An official European Respiratory Society/American Thoracic Society research statement: interstitial pneumonia with autoimmune features, Eur Respir J, 2015;46:976-87.

17. Noth I, Anstrom KJ, Calvert SB, et al., Idiopathic Pulmonary Fibrosis Clinical Research Network (IPFnet), A placebocontrolled randomized trial of warfarin in idiopathic pulmonary fibrosis, Am J Respir Crit Care Med, 2012;186:88-95.

18. Raghu G, Anstrom KJ, King TE Jr, et al., Idiopathic Pulmonary Fibrosis Clinical Research Network, Prednisone, azathioprine and $\mathrm{N}$-acetylcysteine for pulmonary fibrosis, N Eng/ J Med, 2012;366:1968-77.

19. Jackson RM, Glassberg MK, Ramos CF, et al., Sildenafil therapy and exercise tolerance in idiopathic pulmonary fibrosis, Lung, 2010;188:115-23

20. Zisman DA, Schwarz M, Anstrom KJ, et al., Idiopathic Pulmonary Fibrosis Clinical Research Network, A controlled trial of sildenafil in advanced idiopathic pulmonary fibrosis, N Engl Med, 2010;363:620-8.

21. Raghu G, Behr J, Brown KK, et al., ARTEMIS-IPF Investigators, Treatment of idiopathic pulmonary fibrosis with ambrisentan: a parallel, randomized trial, Ann Intern Med, 2013:158:641-9.

22. King TE Jr, Behr J Brown KK, et al., BUILD-1: a randomized placebo-controlled trial of bosentan in idiopathic pulmonary fibrosis, Am J Respir Crit Care Med, 2008:177:75-81.

23. King TE Jr, Brown KK, Raghu G, et al., BUILD-3: a randomized, controlled trial of bosentan in idiopathic pulmonary fibrosis, Am J Respir Crit Care Med, 2011;184:92-9.

24. Raghu G, Million-Rousseau R, Morganti A, et al., MUSIC Study Group, Macitentan for the treatment of idiopathic pulmonary fibrosis: the randomised controlled MUSIC trial, Eur Respir J, 2013:42:1622-32

25. Raghu G, Freudenberger TD, Yang S, et al., High prevalence of abnormal acid gastro-oesophageal reflux in idiopathic pulmonary fibrosis, Eur Respir J, 2006;27:136-42.

26. Tobin RW, Pope CE II, Pellegrini CA, et al., Increased prevalence of gastroesophageal reflux in patients with idiopathic pulmonary fibrosis, Am J Respir Crit Care Med, 1998:158:1804-8.

27. Patti MG, Tedesco P, Golden J, et al., Idiopathic pulmonary fibrosis: how often is it really idiopathic?, I Gastrointest Surg, 2005:9:1053-6.

28. Lee JS, Ryu JH, Elicker BM, et al., Gastroesophageal reflux therapy is associated with longer survival in patients with idiopathic pulmonary fibrosis, Am J Respir Crit Care Med, 2011;184:1390-4

29. Raghu G, Meyer KC, Silent gastro-oesophageal reflux and microaspiration in IPF: mounting evidence for anti-reflux therapy? Eur Respir J, 2012:39:242-5.

30. Janssen W, Pullamsetti SS, Cooke J, et al., The role of dimethylarginine dimethylaminohydrolase (DDAH) in pulmonary fibrosis, I Pathol 2013.229.242-9.

31. Ghebremariam YT, Cooke JP, Gerhart W, et al., Pleiotropic effect of the proton pump inhibitor esomeprazole leading to suppression of lung inflammation and fibrosis, J Trans/ Med, 2015;13:249.

32. Taniguchi $\mathrm{H}$, Ebina $\mathrm{M}$, Kondoh $\mathrm{Y}$, et al., Pirfenidone in idiopathic pulmonary fibrosis, Eur Respir J, 2010;35:821-9.

33. Noble PW, Albera C, Bradford WZ, et al., CAPACITY Study Group, Pirfenidone in patients with idiopathic pulmonary fibrosis (CAPACITY): two randomised trials, Lancet, 2011:377:1760.

34. King TE Jr, Bradford WZ, Castro-Bernardini S, et al., ASCEND Study Group, A phase 3 trial of pirfenidone in patients with idiopathic pulmonary fibrosis, N Eng/ J Med, 2014;370:2083.

35. Lederer DJ, Bradford WZ, Fagan EA, et al., Sensitivity analyses of the change in FVC in a Phase 3 trial of pirfenidone for idiopathic pulmonary fibrosis, Chest, 2015;148:196-201.

36. Costabel U, Albera C, Bradford WZ, et al., Analysis of lung function and survival in RECAP: an open-label extension study of pirfenidone in patients with idiopathic pulmonary fibrosis, Sarcoidosis Vasc Diffuse Lung Dis, 2014;31:198-205.

37. Nathan S, Albera C, Bradford W, et al., Effect Of pirfenidone on Ipf-related mortality outcome measures in patients with idiopathic pulmonary fibrosis (Ipf): Pooled data analysis from the ascend and capacity trials [Abstract], Chest, 2015; Montreal, Canada; 148:391A

38. Gotink KJ, Verheul $\mathrm{HM}$, Anti-angiogenic tyrosine kinase inhibitors: what is their mechanism of action?, Angiogenesis, 2010;13:1-14.

39. Lo Re S, Lecocq M, Uwambayinema F, et al., Platelet-derived growth factor-producing $\mathrm{CD} 4+$ Foxp3+ regulatory $\mathrm{T}$ lymphocytes promote lung fibrosis, Am I Respir Crit Care Med, 2011;184:1270-81.

40. Inoue Y, King TE Jr, Barker E, et al., Basic fibroblast growth factor and its receptors in idiopathic pulmonary fibrosis and lymphangioleiomyomatosis, Am J Respir Crit Care Med 2002:1665:765-73.

41. Richeldi L, Costabel U, Selman M, et al., Efficacy of a tyrosine kinase inhibitor in idiopathic pulmonary fibrosis, N Eng/ I Med 2011;365:1079-87.

42. Richeldi L, du Bois RM, Raghu G, et al., INPULSIS Trial. Investigators, Efficacy and safety of nintedanib in idiopathic pulmonary fibrosis, N Eng/ J Med, 2014;370:2071-82.

43 Raghu G, Rochwerg B, Zhang Y et al., An official ATS/ERS/ JRS/ALAT clinical practice guideline: treatment of idiopathic pulmonary fibrosis. An update of the 2011 clinical practice guideline, Am J Respir Crit Care Med, 2015;192:e3-e19.

44. Kistler KD, Nalysnyk L, Rotella P, Esser D, Lung transplantation in idiopathic pulmonary fibrosis: a systematic review of the literature, BMC Pulm Med, 2014:14:139.

45. Toonkel RL, Hare JM, Matthay MA, Glassberg MK, Mesenchymal stem cells and idiopathic pulmonary fibrosis potential for clinical testing, Am J Resp Crit Care, 2013;188:133-40. 